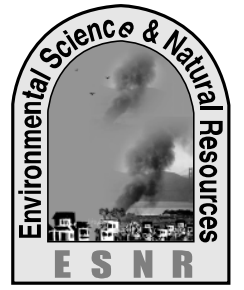

J. Environ. Sci. \& Natural Resources, 5(2): 77- 80, 2012

ISSN 1999-7361

\title{
Sea Surface Temperature Anomaly in the Bay of Bengal in 2010
}

\author{
Shamsad $^{1}$, M. A. Farukh ${ }^{1}$, M. J. R. Chowdhury ${ }^{2}$ and S. C. Basak ${ }^{2}$ \\ ${ }^{1}$ Department of Environmental Science, Bangladesh Agricultural University, Mymensingh-2202 \\ ${ }^{2}$ Institute of Marine Science and Fisheries, University of Chittagong, Chittagong-4331
}

\begin{abstract}
Bangladesh is one of the most disaster prone countries in the world and is a victim of frequent natural calamities like tropical cyclones, tornadoes, floods, storm surges and droughts. Sea surface temperature (SST) plays a vital role in determining oceanatmosphere interaction. In this study we focused on understanding the behavior of SST anomaly prevailed in the region of Bay of Bengal mainly to assume the surface temperature signature for cyclone occurrence. For this study, the observed SST anomaly data were derived from NOAA Coast-watch using a combination of global and regional algorithms. The SST anomaly maps were produced using SAGA-GIS software where the SST lines were fixed at the mean of 30 years data. The AVHRR SST was compared with the climatological SST for the region of Bay of Bengal in 2010. The monthly SST anomaly for 2010 showed average departure of $0.7^{\circ} \mathrm{C}$ for all the months except June and October. It was found that the anomaly increases about $2^{\circ} \mathrm{C}$ at the end of September, and in October the basin bears no significant anomaly.
\end{abstract}

Key words: Anomaly, Bay of Bengal, Cyclone, Sea surface temperature

\section{Introduction}

Tropical cyclogenesis is one of the few atmospheric processes that are poorly understood. The climatological conditions under which tropical cyclones occur have now been well established over decades of research. Several recent publications (Emanuel 1987; 2000; 2005) have shown that the intensity of tropical cyclones is linked with rising sea surface temperature (SST). SST is a difficult parameter to define exactly because the upper ocean $(\sim 10 \mathrm{~m})$ has a complex and variable vertical temperature structure that is related to ocean turbulence and the air-sea fluxes of heat, moisture and momentum. However, SST is the water temperature close to the ocean's surface. The exact meaning of surface varies according to the measurement method used, but it is between $1 \mathrm{~mm}$ (0.04 in) and $20 \mathrm{~m}$ (70 $\mathrm{ft}$ ) below the sea surface where the anomaly is the departure from the normal SST.

SST is an important parameter in oceanography and meteorology due to its major influence on the exchange processes at the air-sea interface. Much of incident in the atmospheric is influenced by the ocean. Departures from normal in the SST are important because they often cause a departure from normal in atmospheric condition. Exchange of heat and mass between the ocean and the atmosphere is strongly dependent on the SST and influences the water and climate conditions on the continental areas. Anomalies in sea temperature scan also lead to anomalies in water. Sea surface temperature is affected by many things, including local weather, currents and seasonal changes. Sea surface temperature anomalies can be used as an indicator of the phase of global climate fluctuations. Two prime examples for ocean affecting the atmosphere are El Niño and Southern Oscillation (ENSO). SST is used only as the boundary condition and is pre specified. The region under consideration is one which has very strong interaction between the atmosphere and ocean.

In-fact in Bangladesh, near the coast of Bay of Bengal is not studied well due to lack of availability of SST data. Therefore, the overall objectives of this piece of work were; to understand the behavior of SST anomaly in the region of Bay of Bengal and analyze the monthly distribution of anomalies of coastal basin, and to investigate the nature of temporal behavior of large scale SST anomalies.

\section{Study area}

\section{Materials and Methods}

The study area Bay of Bengal, is a northern extended arm of the Indian Ocean is located between latitudes $5^{\circ} \mathrm{N}$ and $22^{\circ} \mathrm{N}$ and longitudes $80^{\circ} \mathrm{E}$ and $100^{\circ} \mathrm{E}$ (Fig. 1 ). It is bounded in the west by the east coasts of Sri Lanka and India, on the north by the deltaic region of the Ganges-Brahmaputra-Meghna river system, and on the east by the Myanmar peninsula extended up to the Andaman-Nicobar ridges. The southern boundary of the Bay is approximately along the line drawn from Dondra Head in the south of Sri Lanka to the north tip of Sumatra. The Bay occupies an area of about 2.2 million $\mathrm{km}^{2}$ and the average depth is $2,600 \mathrm{~m}$ with a maximum depth of $5,258 \mathrm{~m}$. Bangladesh is situated at the head of the Bay of Bengal. 


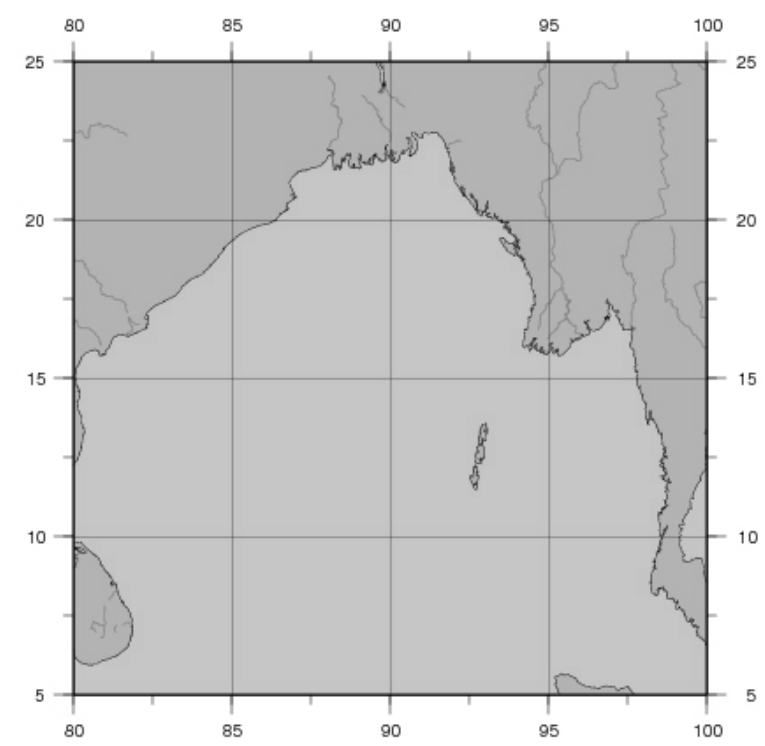

Fig. 1. Study domain of the Bay of Bengal (Latitudes and longitudes posses North and East orientation, respectively)

\section{Data source}

The data source for AVHRR (Advanced Very High Resolution Radiometer) GAC SST is from National Oceanic and Atmospheric Administration (NOAA), National Environmental Satellite Data Information Service (NESDIS), Office of Satellite Data Processing and Distribution (OSDPD). Information on NOAA's POES Satellites can be found at poes website. The source data were derived by methods common to the relevant scientific and technical communities. Information on the processing of AVHRR GAC SST can be found in the predissemination review and documentation from (Foley and Spence, 2005). The climatological data were derived using methods described by Casey and Cornillon (1999). The SST anomaly product is used to show the difference between the sea surface temperature at a given time and the temperature that is normal for that time of year. The Bay of Bengal is a vast area to cover in a single short span study. Effort was optimal to cover the whole area to evaluate the anomalies.

\section{Data mapping and visualization}

The methods employed in the mapping and composite image generation were consistent with techniques suggested by Casey and Cornillon (1999). The data were mapped to an equal angle grid of 0.1 degrees longitude by 0.1 degrees latitude. The mapping was done using simple arithmetic means to produce individual and composite images of various durations (e.g., 1, 3, 8, 14-days, and monthly) following the recommendations of the International Ocean-Color Coordinating Group (Antonie et al., 2004). Graphics and products were generated using the Generic Mapping Tools Software (Wessel and Smith, 1998). The data visualization was done with open source GIS software SAGA-GIS. Further analysis was done using inbuilt statistical tools of the software.

\section{Results and Discussion}

The surface temperature of Bay of Bengal is greatly influenced by the presence of land mass on its three sides. Throughout the year Bay of Bengal the usual water temperature ranges from $25^{\circ} \mathrm{C}$ to $30^{\circ} \mathrm{C}$. In this study, the spatial distribution of SST anomalies of 12 months (Jan-Dec, 2010) is shown in figure 2 and 3. It was observed that the maximum SST anomalies were noticed $\left(1.5\right.$ to $\left.2^{\circ} \mathrm{C}\right)$ in January, May and September. Most of the studied area bears anomalies of $0.7^{\circ} \mathrm{C}$ during the months of January and February. In the North-eastern part, anomalies increased up to $1.5^{\circ} \mathrm{C}$ in January, and up to $1.3^{\circ} \mathrm{C}$ in the Eastern part during February. In upper mid basin and some western coastal region no anomalies were observed in both the months of January and February. Mid basin showed increased anomalies up to $1.3^{\circ} \mathrm{C}$. In May, major part of the basin showed anomalies up to $1.5^{\circ} \mathrm{C}$. The western coastal basin and lower part in the South of basin showed negative anomalies up to $\left(-0.7^{\circ} \mathrm{C}\right)$. Wessel and Smith (1998) used a statistical model to disentangle the two main hurricane predictions - SST and near-surface trade wind speed. Their result indicates that $0.5^{\circ} \mathrm{C}$ increase of SST in August September can gear up an average of $40 \%$ increase in hurricane activity, a measure including both number and severity of tropical Atlantic storms. 

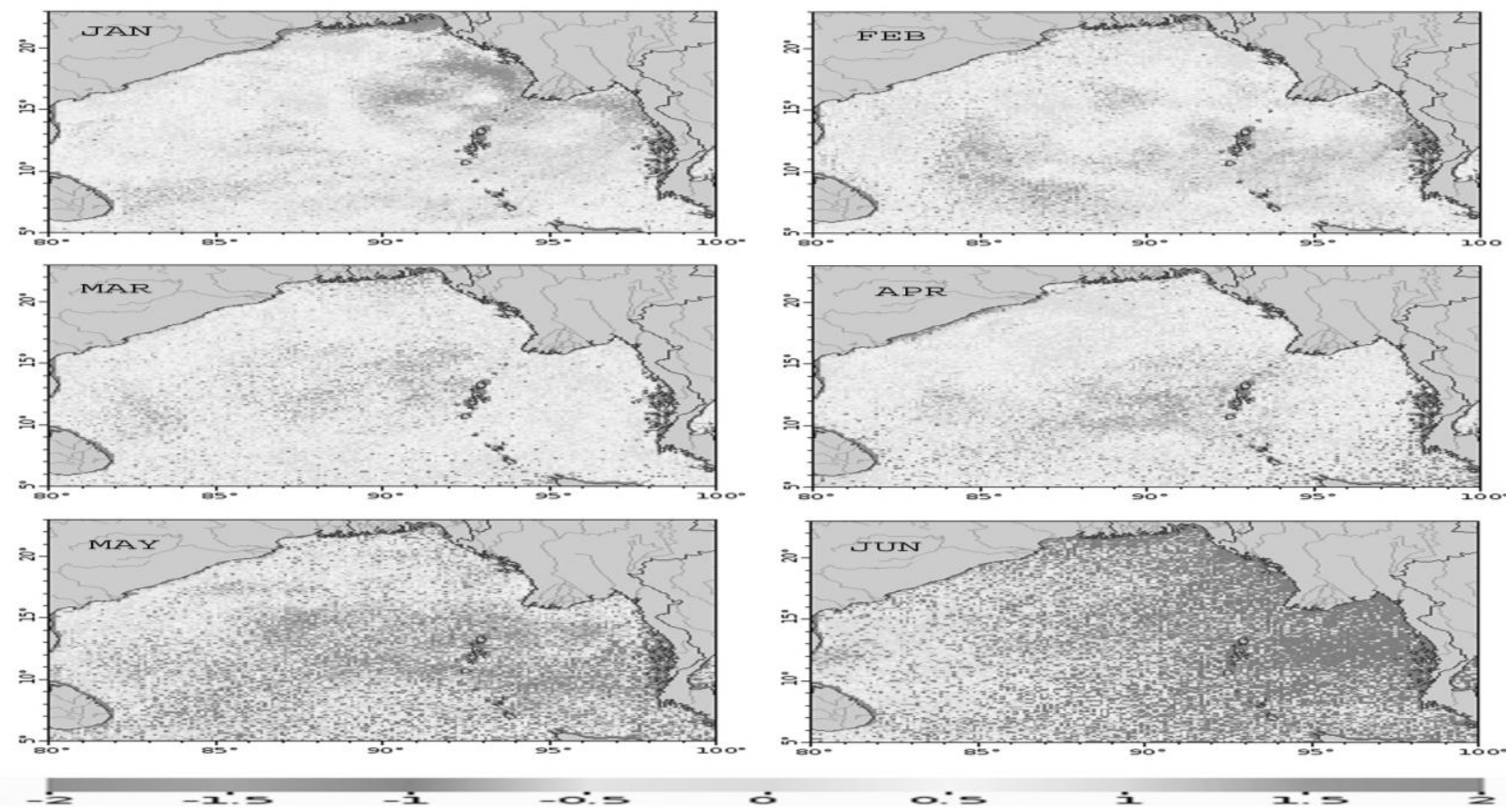

Fig. 2. Spatial distribution of SST anomalies $\left({ }^{\circ} \mathrm{C}\right)$ in 2010 (Jan-Jun).
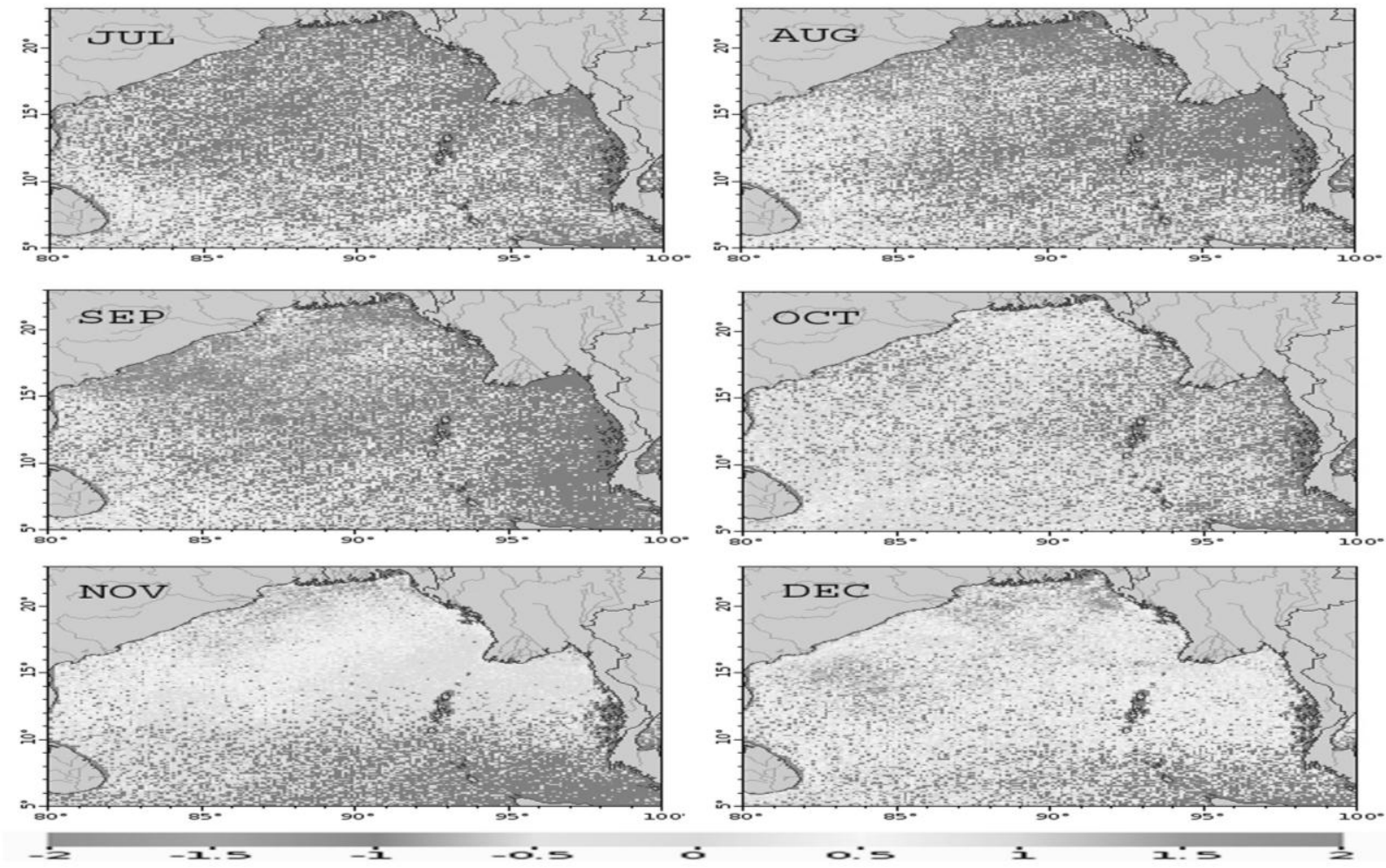

Fig. 3. Spatial distribution of SST anomalies $\left({ }^{\circ} \mathrm{C}\right)$ in 2010 (Jul-Dec). 
Besides the situation described above the minimum SST anomalies were noticed $\left(-0.7\right.$ to $\left.-0.8^{\circ} \mathrm{C}\right)$ in June and October. Mean highest SST anomalies was found in September $\left(2^{\circ} \mathrm{C}\right)$ and the mean lowest $\left(-0.8^{\circ} \mathrm{C}\right)$ in June. By the end of June SST anomaly on the Bay of Bengal increased gradually up to September. No significant anomalies were found in October but SST anomalies increased in November and in December. From North-eastern part there was no significant variation in SST anomaly from January to May. A negative anomaly up to $\left(-0.8^{\circ} \mathrm{C}\right)$ was observed in the mid basin region in June. In July, all part of the basin bears some anomalies, with exception in Western and Eastern most parts. Anomalies in the upper basin varied from 1 to $1.5^{\circ} \mathrm{C}$, whereas negative anomaly (about $-0.4^{\circ} \mathrm{C}$ ) was observed in the Southern part. In the North-western coastal basin anomaly of $1.5^{\circ} \mathrm{C}$ in August further developed and concentrated in the same area where the values increased from 1.5 to $2^{\circ} \mathrm{C}$ in September. Lower part of the basin showed no anomaly during this period. In October, most of the area showed no anomaly but in November, a wide area adjacent to the North-western coast in the upper basin showed anomaly up to $0.7^{\circ} \mathrm{C}$. In December, most of the area showed SST anomalies in Southern part of Bay of Bengal. In upper mid basin these anomalies increased up to $1.3^{\circ} \mathrm{C}$. A significant positive (0.64) relationship was found between the all Bangladesh monsoon rainfall and SST over the Bay of Bengal in June (Ahmed, 2004). Positive SST anomalies are usually related with increased regions of convection (cloudiness and rainfall) while negative SST anomalies are usually with reduced convection. Cyclogenesis is affected by the ocean because this process can rapidly grow when they encounter warm water. Data for this visualization are available from the figure 2 and 3 (May and September).

\section{Conclusions}

A well interpreted SST can be utilized to detect the surface temperature signature for forecasting cyclones. In general, cooling of SST is observed after the passing of a cyclone primarily as a result of surface heat losses. Using long-term observational data records and extensive experimentation with numerical models of various degrees of sophistication, and the complex interactions between the atmosphere and ocean in different geographical settings are now gradually unraveling. Therefore, SST anomaly may be useful in determining local as well as global weather conditions. But to forecast the effects and projections based on this criterion, it needs skilled interpretations and authentic data sources. A single study is not enough to understand such implications. So, further and continuous investigations in this very science are required.

\section{References}

Ahmed, S. 2004. The relationship between sea surface temperature in the Bay of Bengal and Monsoon rainfall in Bangladesh, 1912-2001. MS thesis, Deptt. of Geography, Ohio University, 2p.

Antoine, D.; Campbell, J. W.; Evans, R. H.; Gregg, W. W.; Lewis, M. R.; Morel, A.; Moulin, C. and Murakami, H. 2004. Guide to the creation and use of Ocean Color, Level-3, binned data Products. IOCCG Report Number 4.

Bjerknes, J. 1969. Atmospheric teleconnections from the equatorial Pasific. Mon. Wea. Rev., 97, 163172.

Casey, K. S. and Cornillon, P. 1999. A Comparison of satellite and in situ based sea surface temperature climetologies. Journal of Climate. Vol. 12, no. 6, 1848-1863.

Emanuel, K. A. 1987. The dependency of hurricane intensity on climate, Nature, 326: 483-485.

Emanuel, K. A. 2000. A statistical analysis of tropical cyclone intensity, Mon. Wea. Rev. 128: 11391152.

Emanuel, K. A. 2005. Increasing destructiveness of tropical cyclones over the past 30 years, Nature, 336: 686-688.

Foley, D. G. and Spence. L. J. 2005. CoastWatch Advanced Very High Resolution Radiometer (AVHRR) Global Area Coverage (GAC) Sea Surface Temperature Data. Section 515 predissemination review and documentation form (5/2003). NOAA Fisheries Service, Southwest Fisheries Science Center. La Jolla, CA.

Wessel, P. and Smith. W. H. 1998. New, improved version of the Generic Mapping Tools released, EOS Trans. AGU, 79, 579. 